\title{
SISTEM KONTROL NUTRISI FLOATING HYDROPONIC SYSTEM KANGKUNG (Ipomea reptans) MENGGUNAKAN INTERNET OF THINGS BERBASIS TELEGRAM
}

\section{CONTROL SYSTEM OF NUTRIENT IN FLOATING HYDROPONIC SYSTEM FOR WATER SPINACH (Ipomea reptans) USING TELEGRAM-BASED IoT}

\author{
Anri Kurniawan ${ }^{1 凶}$, Hanis Adila Lestari ${ }^{1}$ \\ ${ }^{1}$ Program Studi Teknik Pertanian dan Biosistem, Fakultas Sains dan Teknologi, \\ Universitas Nahdlatul Ulama Purwokerto.

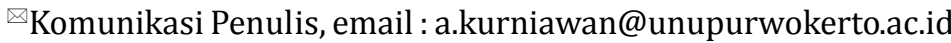 \\ DOI:http://dx.doi.org/10.23960/jtep-lv9i4.326-335
}

Naskah ini diterima pada 16 September 2020; revisi pada 27 November 2020; disetujui untuk dipublikasikan pada 16 Desember 2020

\begin{abstract}
Nutrient water in the reservoir of floating hydroponic system serves to meet the nutritional needs of hydroponic plants. Continuous circulation for 24 hours causes the water level to decrease due to the evaporation process in plants, resulting in reduced reservoir water every day. The research was conducted by designing a monitoring tool for water level and nutrient of water spinach (Ipomea reptans) on floating hydroponics through the telegram application. Ultrasonic Sensor HC-SRO4 as water level reader and sensor TDS DFrobot as a nutrient reader and 2 channel relay as an automatic on-off pump for water and nutrients. The telegram API bot through the botfather is synchronized with nodeMCU-ESP32 so that it can be controlled via the internet of things (IoT) system. Telegram can receive and request information on water levels, TDS, pump status, start and stop water pumps, and nutrients. The water pump is "on" at a height of less than $15 \mathrm{~cm}$ and the pump is "off" at a height of above $20 \mathrm{~cm}$, while for the nutrient pump it is "on" at a TDS value of less than 500ppm and "off" at a TDS value above 1000ppm. In ultrasonic sensor testing, an error of $0 \%$ was obtained, while in TDS sensor testing, an error of 0-04\% and 0-05\% was obtained. The hydroponic raft of floating water spinach at the age of 30 HST reached an average plant height of $52.63 \mathrm{~cm}$ and a total weight of 31.25 grams.
\end{abstract}

Keywords: floating, hydroponic, IoT, telegram, water spinach

\begin{abstract}
ABSTRAK
Air nutrisi pada reservoir hidroponik rakit apung berfungsi untuk memenuhi kebutuhan nutrisi tanaman hidroponik. Sirkulasi yang terus menerus selama 24 jam menyebabkan ketinggian air berkurang akibat proses evaporasi pada tanaman, mengakibatkan air reservoir berkurang tiap harinya. Penelitian dilakukan dengan merancang alat monitoring ketinggian air dan nutrisi tanaman kangkung (Ipomea reptans) pada hidroponik rakit apung melalui aplikasi telegram. Sensor Ultrasonik HC-SR04 sebagai pembaca level air dan Sensor TDS DFRobot sebagai pembaca pekatan nutrisi serta relay 2 channel sebagai on-off otomatis pompa air dan nutrisi. Bot telegram API melalui botfather disinkronkan dengan nodeMCU-ESP32 sehingga dapat dikontrol melalui sistem internet of things (IoT). Telegram dapat menerima dan meminta informasi tinggi air, TDS, status pompa, menghidupkan dan mematikan pompa air serta nutrisi. Pompa air "on" pada ketinggian kurang dari $15 \mathrm{~cm}$ dan pompa "off" pada ketinggian di atas $20 \mathrm{~cm}$, sedangkan untuk pompa nutrisi “on" pada nilai TDS kurang dari 500 ppm dan "off" pada nilai TDS di atas 1000 ppm. Pada pengujian sensor ultrasonik didapatkan error 0\%, sedangkan pada pengujian sensor TDS didapat error 0-0,4 \% dan 0-0,5\%. Tanaman kangkung hidroponik rakit apung pada umur 30 HST mencapai rata-rata tinggi tanaman 52,63 cm dan bobot total basar sebesar 31,25 gram.
\end{abstract}

Kata Kunci: floating, hidroponik, IoT, kangkung, telegram 


\section{PENDAHULUAN}

Tanaman kangkung (Ipomea reptans) merupakan salah satu jenis sayuran daun dengan nilai gizi yang tinggi sehingga banyak dikonsumsi oleh masyarakat Indonesia. Sistem hidroponik dapat meningkatkan produktivitas kangkung yang signifikan, sehingga budidaya tanaman secara hidroponik dapat dimaksimalkan dengan baik untuk kebutuhan masyarakat (Hidayati et al., 2017). Menurut ensiklopedia hidroponik (Bayu, 2016) tabel pH dan ppm tanaman kangkung adalah 5,5 - 5,5 dan 1050 ppm - 1400 ppm.

Upaya peningkatan produksi salah satunya dilakukan dengan meningkatkan metode penanaman sayuran secara hidroponik dengan pengaturan nutrisi pertumbuhan (Wahome et al, 2011). Budidaya hidroponik memiliki banyak sistem, yaitu sistem sumbu (wick), deep flow technique (DFT), nutrient film technique (NFT), pasang surut (ebb \& flow), irigasi tetes (drip irrigation), rakit apung (floating hydroponic raft system) dan aeroponik. Kangkung hidroponik dapat dipanen 27 hari setelah tanam dan dapat dipanen kembali secara berkala 5 hari sekali dan memiliki tinggi tanaman $47 \mathrm{~cm}$ dan bobot basah 36 gram (Susilawati, 2019).

Hidroponik rakit apung atau floating hidroponic system atau floating hydroponic raft system atau water culture system adalah sistem hidroponik yang memanfaatkan air dengan jumlah banyak pada bak penampungan, sebagai tempat tumbuh dan berkembangnya tanaman. Sistem rakit apung merupakan budidaya tanaman dengan cara menanamkan atau memasukan tanaman pada lubang tanam yang mengapung di atas Styrofoam. Styrofoam mengapung permukaan larutan nutrisi dalam bak penampung menggunakan aerator untuk memasukan oksigen ke dalam air (Sunardi dan Adimihardja, 2013).

Sistem hidroponik rakit apung pada prosesnya harus memperhatikan air dalam bak penampung, ketinggian air dan kandungan nutrisi dalam air. Pengukuran laju pertumbuhan secara manual banyak memiliki kekurangan, sehingga dapat dihindari dengan teknologi informasi seperti penggunaan sensor, mikrokontroler dan internet of things (IoT). Pengukuran tinggi muka air dapat menggunakan sensor ultrasonik dan kondutivitas air nutrisi terlarut menggunakan sensor total dissolved solid (TDS) (Wulansari dan Baskara, 2019).

Penggunaan water level dan total dissolved solid (TDS) pada hidroponik rakit apung terdapat bak penampung yang mengalami sirkulasi secara terus menerus, sehingga mengakibatkan evaporasi. Selain menggunakan sensor ultrasonik dan TDS, kontrol pertumbuhan kangkung juga dapat menggunakan kamera yang terhubung dengan mikrokontroler yang dapat memberikan informasi ke user melalui internet. Salah satu aplikasi yang dapat mendukung pemograman melalui jaringan internet adalah bot telegram pada telegram messenger, sehingga laju pertumbuhan tanaman dapat dimonitor dari jarak jauh. Pemanfaatan internet of things pernah dilakukan pada budidaya ikan lele menggunakan raspberry phi (Rohadi et al., 2018).

Berdasarkan uraian tersebut, bahwa metode tersebut dapat dikembangkan untuk mengukur parameter pertumbuhan tanaman dan ketersediaan air dan nutrisi dalam bak. Hal ini bertujuan untuk memperoleh hasil pengamatan yang akurat dan berkelanjutan dalam proses pertumbuhan kangkung hidroponik (Ipomea reptans) sehingga produksi kangkung optimal. Tujuan dari penelitian ini adalah merancang alat monitoring ketinggian air dan total dissolved solid (TDS) menggunakan mikrokontroler nodeMCU ESP-32 dan bot telegram; menguji coba sistem monitoring ketinggian air dan total dissolved solid (TDS) pada hidroponik rakit apung menggunakan telegram; mengimplementasikan sistem monitoring ketinggian air dan TDS pada hidroponik rakit apung menggunakan tanaman kangkung; dan mengukur laju pertumbuhan tanaman kangkung hidroponik rakit apung menggunakan aplikasi telegram.

\section{BAHAN DAN METODE}

\subsection{Tahapan Penelitian}

Tahapan Penelitian dilakukan dengan beberapa tahapan yaitu studi literatur, perancangan alat, 
analisis, implementasi teknologi, pengumpulan data, perancangan aplikasi dan uji coba alat. Lebih lengkap dapat dilihat pada diagram fishbone penelitian di bawah ini (Gambar 1).

\subsection{Perancangan Perangkat Keras}

Perangkat keras terdiri dari input dan output, perangkat input sistem monitoring water level dan laju pertumbuhan kangkung hidroponik rakit apung menggunakan IoT berbasis telegram yaitu terdiri dari sensor ultrasonik, sensor total dissolved solid (TDS), kamera raspberry phi dan kamera $360^{\circ}$. Sedangkan untuk perangkat output adalah pompa air dan pompa nutrisi serta informasi pada telegram berupa teks dan gambar. Blok diagram arsitektur sistem deteksi ketinggian air dan nutrisi dapat dilihat pada Gambar 2.

Rangakaian perangkat keras hidroponik rakit apung (Gambar 2) memiliki peran dan fungsi yang berbeda-beda agar sistem dapat bekerja dengan baik. Berikut merupakan penjelasan masing-masing bagian tersebut:

1. Sensor ultrasonic berfungsi sebagai sensor untuk mengukur ketinggian air.

2. Sensor TDS berfungsi sebagai sensor untuk mengukur pekatan nutrisi dalam air dalam satuan part per million (ppm).

3. ESP32 berfungsi sebagai pengontrol dan pemroses data dan mengirimkannya ke telegrambot melalui jaringan internet.

4. Telegram berfungsi menampilkan data ketinggian air, TDS dan citra laju pertumbuhan.

5. Relay berfungsi untuk mengendalikan ON/ OFF peralatan listrik berdaya besar, baik dari arus atau tegangan $\mathrm{AC}$ maupun DC.

6. Pompa air berfungsi untuk mentransfer air dari tendon air yang satu ke bak tempat penampungan hidroponik rakit apung.

7. Pompa nutrisi berfungsi untuk mentransfer air nutrisi dari tendon nutrisi yang satu ke bak

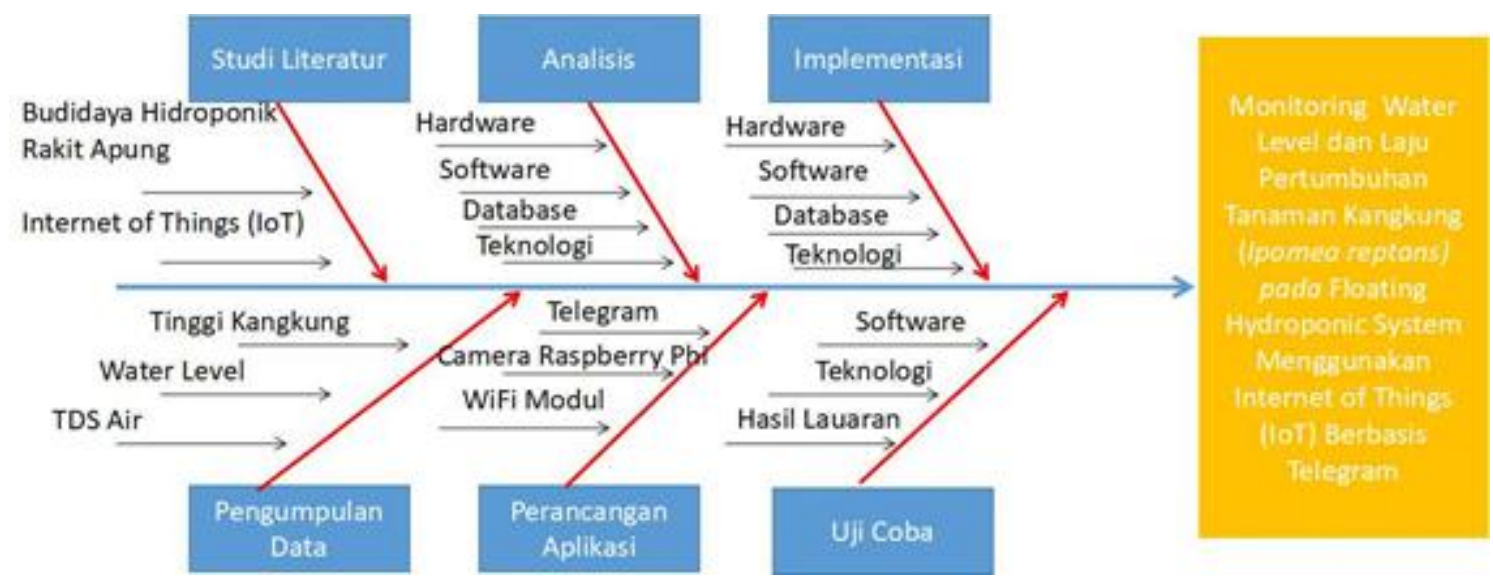

Gambar 1. Diagram Fishbone Penelitian
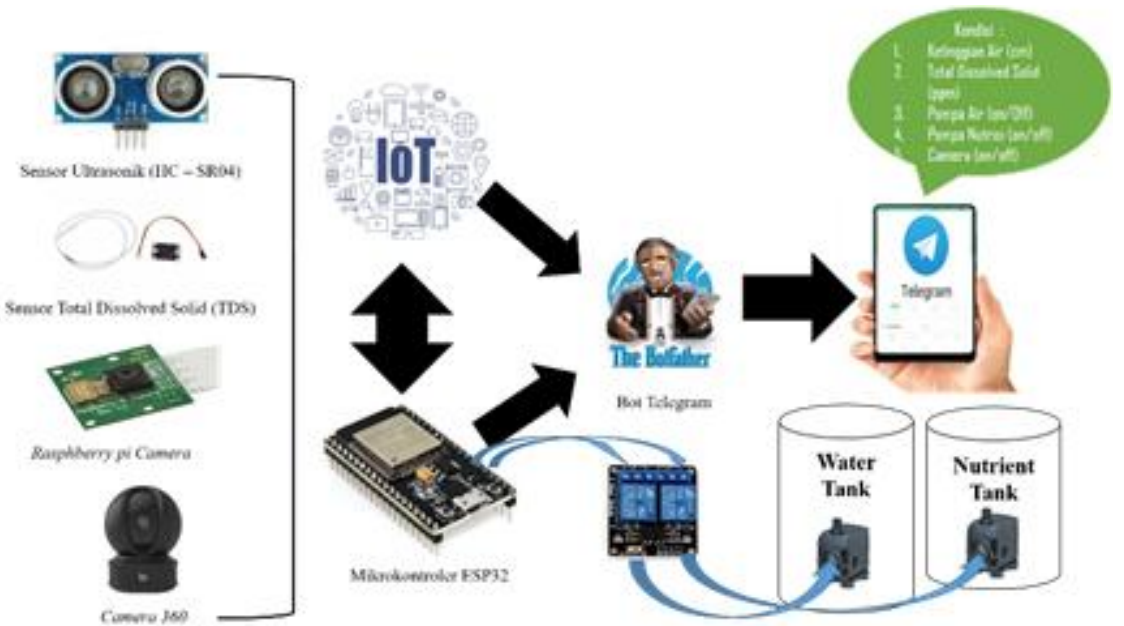

Gambar 2. Rangkaian Perangkat Keras (Hardware) 
tempat penampungan hidroponik rakit apung.

Perangkat keras pendukung dalam sistem hidroponik rakit apung adalah:

1. Screen House berfungsi untuk menutupi hidroponik rakit apung supaya tidak terkena air hujan yang terbuat dari baja ringan dan plastik UV.

2. Bak Penampung (Reservoir) berfungsi untuk menampung air nutrisi tempat tanaman kangkung hidup.

3. Pompa Venturi berfungsi memberikan tekanan udara pada bak penampung agar terjadi sirkulasi dalam air.

4. Aerator berfungsi menghasilkan gelembung udara untuk tambahan oksigen pada bak penampung.

5. Styrofoam berfungsi menahan tanaman dalam netpot agar melayang dalam air sehingga tanaman tumbuh optimal.
6. Netpot untuk menyimpan tanaman kangkung sebagi pot yang terpasang pada lubang sterefoam.

7. Rockwool berfungsi sebagai media tanaman kangkung.

\subsection{Perancangan Perangkat Lunak}

Perangkat lunak (Software) berfungsi ketika sistem dijalankan dengan melakukan inisiasi terhadap nilai sensor dan memuat data pengolahan air. Gambar 3 menampilkan diagram alir system. Telegram bot adalah core yang tersedia pada aplikasi telegram dalam bentukAPI, yang memungkinkan siapapun membuat bot yang kemudian akan membalas semua penggunanya jika mengirimkan pesan berupa perintah yang diterima bot. Telegram bot (botfather) memiliki banyak metode dalam membuat sebuah bot di Telegram di antaranya sendMessage, forwardMessage, sentPhoto atau beberapa perintah lain yang dikombinasikan dengan mikrokontroler melalui nodeMCU ESP32

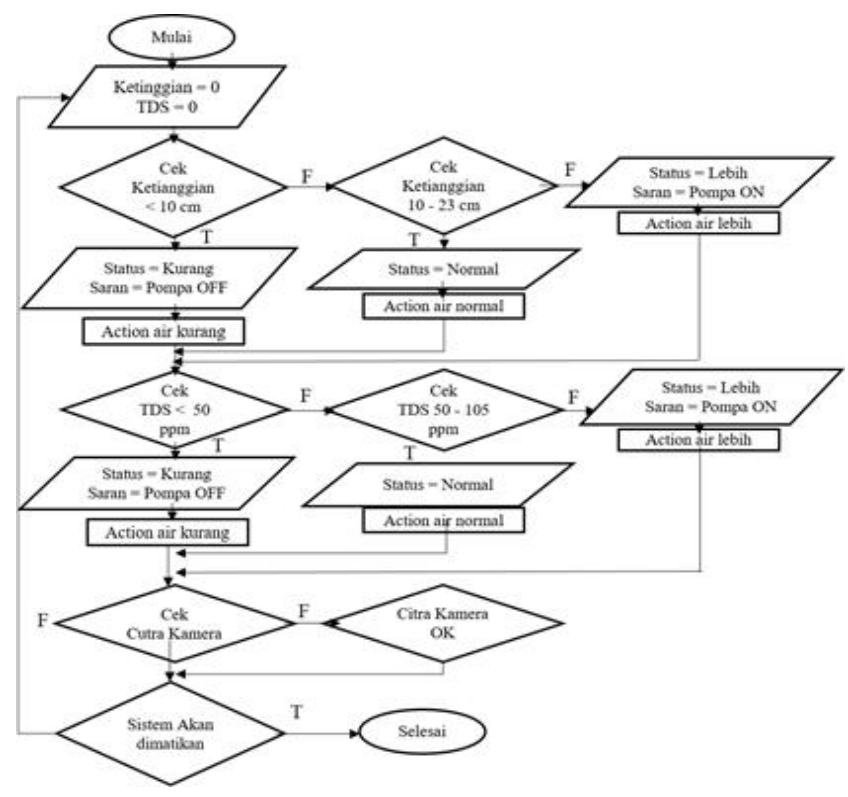

Gambar 3. Diagram Alur Sistem

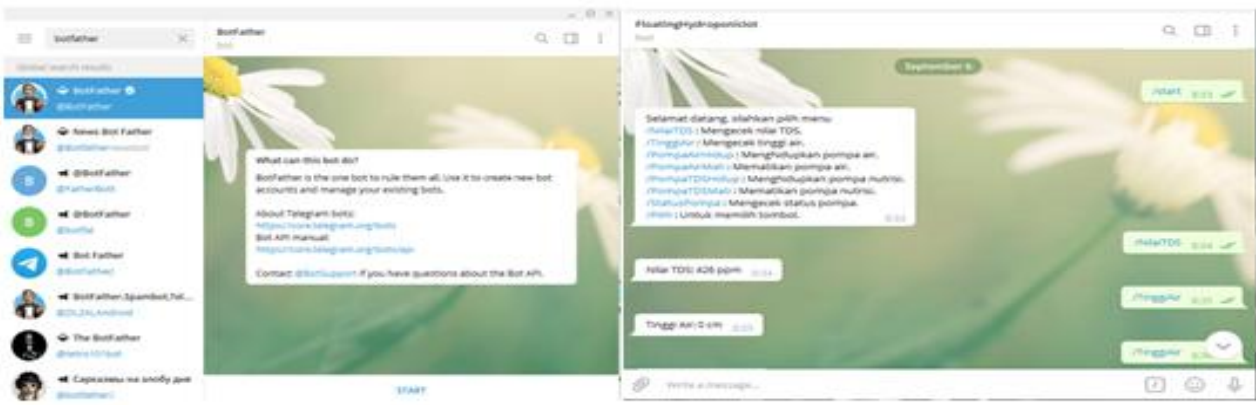

Gambar 4. Tampilan Telegram Bot 
sehingga dapat menjalan kerja jarak jauh (Cokrojoyo et al., 2017). Tampilan perintah (Gambar 4) bot dapat di-custom berupa mengetik perintah, mengklik perintah yang sudah diketik ataupun model klik dalam pilihan perintah.

\subsection{Pengukuran dan Analis Data}

Pengukuran yang dilakukan pada penelitian dapat dilihat pada Tabel 1. Analisa data penelitian untuk mencari hubungan antar parameter yang mempengaruhi kinerja hidroponik rakit apung. Data pengujian yang terkumpul diolah menggunakan analisis regresi hasil pengukuran pada hari ke 1 sampai dengang hari ke 30 dengan aplikasi ms excel. Kemudian dilakukan analysis of varians (ANOVA) mengunakan aplikasi SPSS 26 untuk membandingkan hasil pengukuran secara manual, tampak LCD dan data yang ada pada aplikasi telegram. Uji lanjut (post hoc test) menggunakan Least Significance Different (LSD), Uji Tukey dan Duncan Multiple Range Test (DMRT) dengan level signifikasi 0.05.

\section{HASIL DAN PEMBAHASAN}

\subsection{Implementasi Teknologi}

Implementasi sistem secara keseluruhan dilaksanakan setelah semua perangkat lunak dan perangkat keras terpasang sesuai dengan desain. Parameter yang diukur adalah sensor ketinggian air menggunkan sensor ultrasonic dan sensor total dissolved solid (TDS). Data dari sensor direspon dan diproses oleh mikrokontroler arduino ESP32, mikrokontroler memberikan informasi ke aplikasi telegram melalui jaringan internet. Mikrokontroler secara otomatis menghidupkan dan mematikan pompa air dan pompa nutrisi berdasarkan pembacaan sensor menggunakan timer pada pukul 08.00 dan pukul 13.00. Sistem on/off pompa dapat dikendalikan melalui aplikasi telegram berdasarkan informasi ketinggian air dan TDS yang terdapat pada menu chat telegram melalui perintah on/off. Data informasi pengukuran sensor juga dapat ditampilkan pada LCD, diteliti tingkat kecocokannya dengan pengukuran manual menggunakan penggaris dan TDS meter.

Tabel 1. Variabel Pengukuran Monitoring Kangkung Hidroponik Rakit Apung

\begin{tabular}{cllc}
\hline No. & \multicolumn{1}{c}{ Pengukuran } & \multicolumn{1}{c}{ Alat Ukur } & Satuan \\
\hline 1. & Ketinggian Air & Water Level Indikator & $\mathrm{cm}$ \\
2. & Total Dissolved Solid (TDS) & TDS meter & $\mathrm{ppm}$ \\
3. & pH air & pH marer air & $\mathrm{pH}$ \\
4. & Suhu & TDS meter & $0 \mathrm{C}$ \\
5. & Tinggi tanaman & Mistar & $\mathrm{cm}$ \\
6. & Lebar daun & Micrometer skrup & $\mathrm{cm}$ \\
7. & Bobot basah tanaman & Timbangan Digital & gram \\
\hline
\end{tabular}

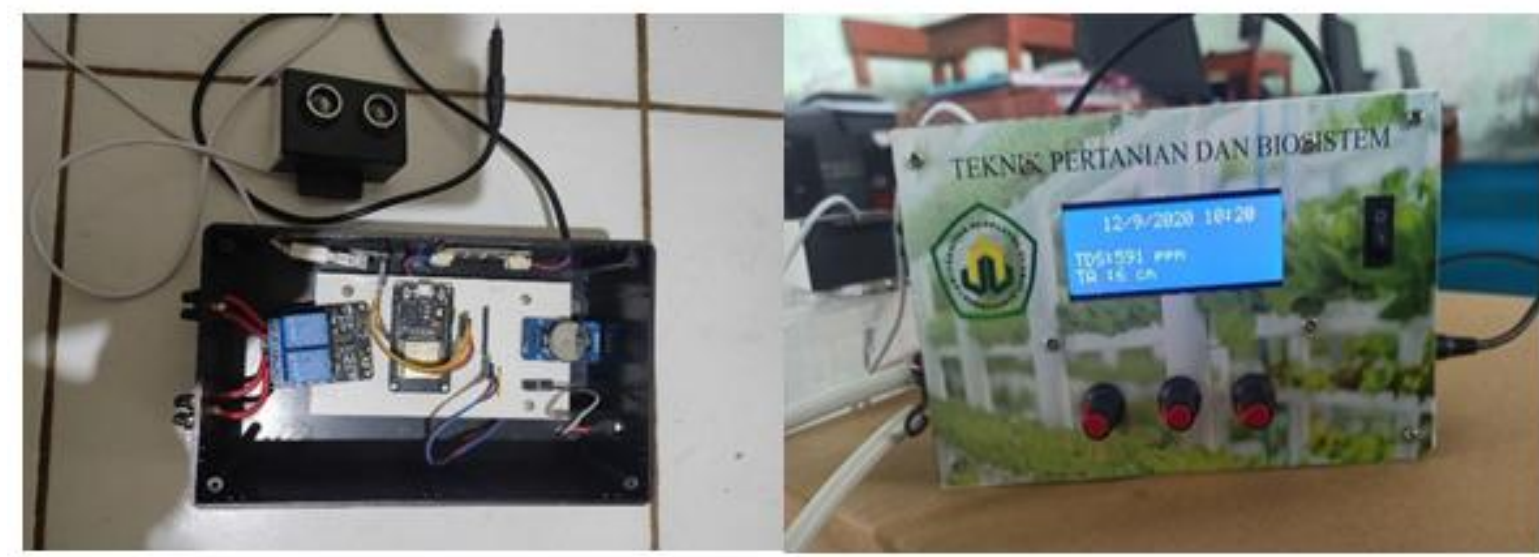

Gambar 5. Implementasi Rangkaian Sensor Ultra-sonik dan TDS 


\subsection{Internet of Things Telegram}

Botfather adalah bot telegram yang merupakan bawaan dari aplikasi telegram itu sendiri, dalam membuat program telegram dapat dilakukan dengan coding dan tanpa coding. Botfather yang sudah mendapatkan token API kemudian dapat diakses dan dikombinasikan ke dalam software Arduino IDE. Arduino IDE adalah perangkat dalam memprogram mikrokontroler Arduino ESP32. Bot telegram yang dirancang diberi nama bot "FloatingHydroponicIoT" yang dapat diakses oleh semua user telegram dapat mengakses bot telegram.

Perintah yang terdapat pada bot telegram yang dapat diakses dengan memasukan kode sebagai berikut:

/NilaiTDS untuk mengecek nilai TDS, /TinggiAir untuk mengecek tinggi air, /PompaAirHidup untuk menghidupkan pompa air,

/PompaAirMati untuk mematikan pompa air, /PompaTDSHidup untuk menghidupkan pompa nutrisi,
/PompaTDSMati untuk mematikan pompa nutrisi,

/StatusPompa untuk mengecek status pompa /Pilih untuk memilih tombol pada layar chat Semua perintah dapat diakses dengan 3 cara, pertama dengan mengetik sesuai perintah, kedua dengan mengklik perintah yang tersedia berwarna biru dan ketiga klik tombol yang tersedia di layar setelah mengetikan /Pilih.

\subsection{Hidroponik Rakit Apung}

Floating hydroponic raft system (FHRS) atau deep water culture atau orang Indonesia menyebutnya dengan hidroponik rakit apung adalah salah satu model hidroponik yang banyak diimplementasikan di masyarakat. Floating hydroponic yaitu menanam tanaman dengan membuat tanaman mengapung pada air nutrisi bak penampungan dengan penyangga styrofoam. Penyangga tanaman tidak harus menggunakan bahan Styrofoam, asalkan pada prinsipnya massa jenis penyangga lebih kecil daripada air nutrisi sehingga dapat menopang
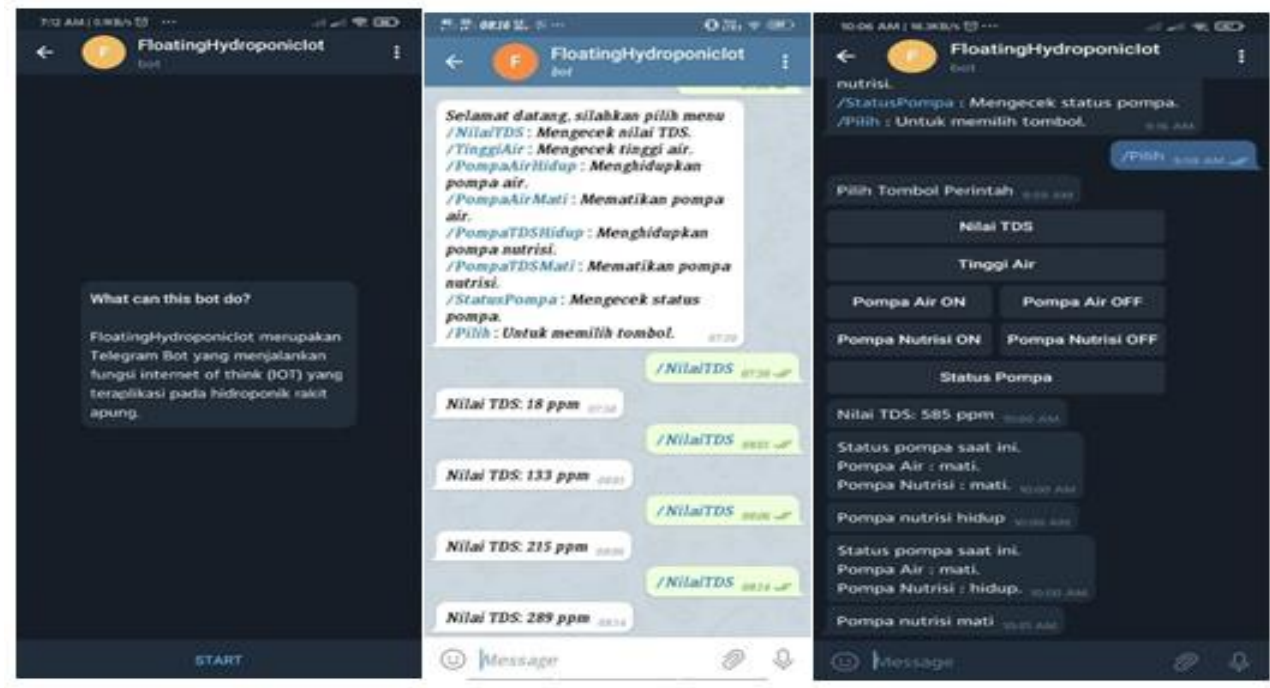

Gambar 6. Tampilan Chat Telegram

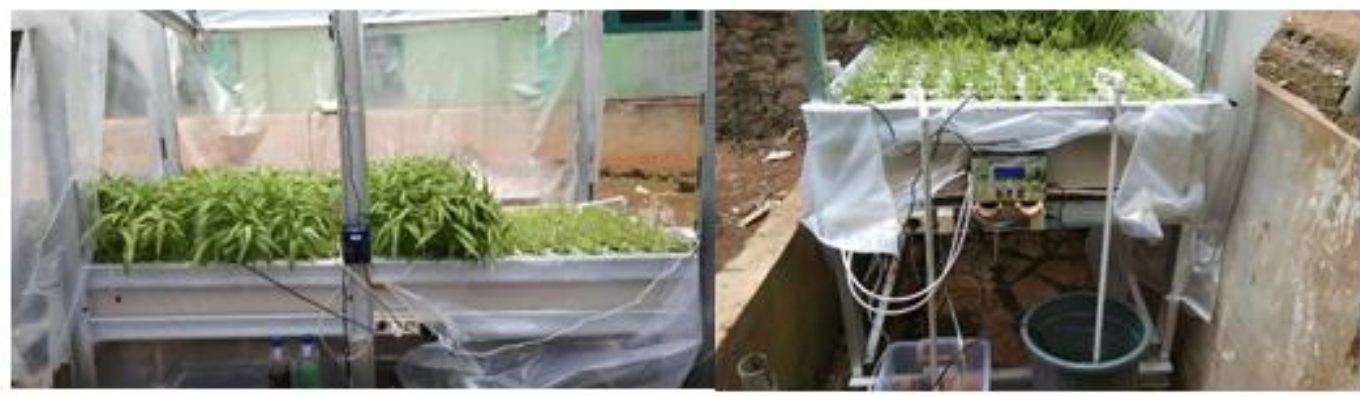

Gambar 7. Hidroponik Rakit Apung Otomatis 
beban tanaman ketika sudah besar. Akar tanaman langsung menyentuh dan tenggelam pada air nutrisi, tanpa menggunakan kain flannel. Aerasi yang bagus dan merata menyebabkan pertumbuhan tanaman sangat cepat dan bobot yang lebih besar. Akar yang tumbuh memanjang dan berwarna putih bersih adalah tanda akar cukup kandungan oksigen dalam air. Pada hidroponik rakit apung, penyangga mengalami penurunan seiring berkurangnya air nutrisi pada bak tanaman, hal itu disebabkan oleh proses evapotranspirasi tanaman. Rakit apung membutuhkan volume air yang sangat besar, sehingga menyebabkan suhu air nutrisi pada siang hari tidak terlalu tinggi. Massa jenis air sekitar $1000 \mathrm{~kg} / \mathrm{m}^{3}$ dengan $1 \mathrm{~m}^{3}$ samadengan 1000 liter air dengan kata lain 1 liter air beratnya sekitar $1 \mathrm{~kg}$. Ukuran rakit apung 2 meter x 1 meter $x 0,25$ meter $=0,4 \mathrm{~m}^{3}$ atau sama dengan 500 liter air, kondisi tersebut menyababkan kontruksi rakit apung harus kuat dan kokoh.

\subsection{Water Level}

Pengukuran ketinggian air (water level) pada bak penampung dilakukan dalam monitoring jumlah air nutrisi pada hidroponik rakit apung. Sensor yang digunakan dalam mengukur water level air adalah dengan sensor ultrasonic HC-SR04 yang disimpan di atas styrofoam dengan memancarkan gelombang ultrasonic ke permukaan air. Karakteristik linieritas sensor ultrasonic diuji dalam mengukur jarak pada ketinggian air bak dengan akurat Sistem kendali water level adalah sensor mendeteksi ketinggian air, jika air di atas $20 \mathrm{~cm}$ maka akan memberikan notifikasi ke telegram dan pompa akan off secara otomatis. Jika ketinggian air kurang dari $15 \mathrm{~cm}$ maka akan memberikan notifikasi pompa on, selain user dapat menentukan kapan pompa akan hidup dan mati. Pengujian dengan menempatkan sensor di atas bak air percobaan kemudian diukur pada tinggi air yang berbeda-beda dan dibandingkan dengan pengukuran menggunakan mistar atau meteran.
Sistem otomatisasi pada monitoring ketinggian air dikontrol menggunakan range ketinggian yang dapat diatur serta pada timer waktu yang ditentukan. Pompa air akan hidup jika ketinggian air kurang dari $15 \mathrm{~cm}$ dan pompa akan mati jika melebihi ketinggian diata s $20 \mathrm{~cm}$. Pompa air akan hidup pada timer pukul 08.00 dan puku 13.00 apabila ketinggian air dibawang $20 \mathrm{~cm}$ dan akan kembali mati jika ketinggian air mencapai 20 $\mathrm{cm}$.

Hasil pengujian pengukuran sensor ultrasonik HC-SR04 dengan penggaris/mistar sebagai alat ukur pembanding dilakukan sebanyak 14 kali dan dapat dilihat pada Tabel 3. Data didapat adalah hasil error sebesar 0\% sehingga menunjukan hasil pengujian akurat. Pengukuran dilakukan dengan meletakan sensor dengan alat ukur (penggaris) sama rata dengan ketinggiannya.

\subsection{Total Dissolved Solids (TDS)}

Total Dissolved Solids (TSD) adalah salah satu cara pengukuran untuk mengukur total larutan nutrisi yang terlarut dalam air, selain TDS pengukuran dapat dilakukan dengan electrical conductivity (EC) meter. Proses pengujian nutrisi dalam bak penampung dilakukan dengan membandingkan sensor TDS dengan alat ukur TDS meter merk TDS-3 dan TDS EC meter yang keduanya dicelupkan kedalam air pada bak penampung.

Air bak percobaan kemudian diberi laruran nutrisi dengan perbandingan $1 \mathrm{ml}, 2 \mathrm{ml}, 3 \mathrm{ml}, 4$ $\mathrm{ml}, 5 \mathrm{ml}$ dan $10 \mathrm{ml}$ dengan setiap larutan terdiri dari 50\% larutan stok A dan 50\% stok larutan B. Pengukuran dilakukan dengan membandingkan nilai pada TDS-3 dengan tampilan di LCD dan juga pada chat aplikasi telegram. Pemberian larutan AB mix yang ditambahkan setiap perubahan dosis dengan volume air tetap yaitu 1 liter.

Tabel 2. Saran Pengukuran Ketinggian Air dan TDS

\begin{tabular}{ccccc}
\hline No. & Nilai Ketinggian Air & Range Ketinggian Air & Status & Saran \\
\hline 1 & $<15$ & $15 \mathrm{~cm}-20 \mathrm{~cm}$ & Air Kosong & Pompa Hidup \\
2 & $>20$ & $15 \mathrm{~cm}-20 \mathrm{~cm}$ & Air Penuh & Pompa Mati \\
\hline
\end{tabular}


Tabel 3. Hasil Pengujian dengan Sensor Ultrasonic

\begin{tabular}{cccccc}
\hline No. & \multicolumn{5}{c}{ Pengukuran } \\
\cline { 2 - 6 } & $\begin{array}{c}\text { Water Level } \\
\text { Indikator (cm) }\end{array}$ & $\begin{array}{c}\text { Sensor Ultrasonik } \\
\text { (cm) LCD }\end{array}$ & $\begin{array}{c}\text { Sensor Ultrasonik } \\
\text { (cm) Telegram }\end{array}$ & Selisih & $\begin{array}{c}\text { Error } \\
\text { (\%) }\end{array}$ \\
\hline 1 & 1 & 1 & 1 & 0 & 0 \\
2 & 2 & 2 & 2 & 0 & 0 \\
3 & 3 & 3 & 3 & 0 & 0 \\
4 & 5 & 5 & 5 & 0 & 0 \\
5 & 10 & 10 & 10 & 0 & 0 \\
6 & 15 & 15 & 15 & 0 & 0 \\
7 & 16 & 16 & 16 & 0 & 0 \\
8 & 17 & 17 & 17 & 0 & 0 \\
9 & 18 & 18 & 18 & 0 & 0 \\
10 & 19 & 19 & 19 & 0 & 0 \\
11 & 20 & 20 & 20 & 0 & 0 \\
12 & 21 & 21 & 21 & 0 & 0 \\
13 & 22 & 22 & 22 & 0 & 0 \\
14 & 23 & 23 & 23 & 0 & 0 \\
\hline
\end{tabular}

Tabel 4. Saran Pengukuran Ketinggian Air dan TDS

\begin{tabular}{ccccc}
\hline No. & Nilai TDS & Range ppm & Status & Saran \\
\hline 1 & $<500$ & $500-1000 \mathrm{ppm}$ & TDS Rendah & Pompa Hidup \\
2 & $>1000$ & $500-1000 \mathrm{ppm}$ & TDS Tinggi & Pompa Mati \\
\hline
\end{tabular}

Tabel 5. Hasil Pengujian Sensor TDS DFrobot dengan TDS-3

\begin{tabular}{cccccc}
\hline No. & \multicolumn{5}{c}{ Pengukuran } \\
\cline { 2 - 6 } & $\begin{array}{c}\text { TDS meter } \\
\text { (ppm) }\end{array}$ & $\begin{array}{c}\text { TDS Sensor } \\
\text { (ppm) LCD }\end{array}$ & $\begin{array}{c}\text { TDS Sensor } \\
(\mathbf{p p m}) \text { Telegram }\end{array}$ & Selisih & Error (\%) \\
\hline 1 & 18 & 18 & 18 & 0 & 0 \\
2 & 133 & 132 & 132 & 1 & 0.01 \\
3 & 224 & 220 & 220 & 4 & 0.04 \\
4 & 280 & 278 & 278 & 2 & 0.02 \\
5 & 293 & 294 & 294 & 1 & 0.01 \\
6 & 368 & 370 & 370 & 2 & 0.02 \\
7 & 257 & 462 & 462 & 5 & 0.05 \\
8 & 101 & 999 & 999 & 2 & 0.02 \\
\hline
\end{tabular}

Hasil pengujian sensor TDS dan TDS meter merk TDS 3 ditampilkan pada Tabel 5 didapat nilai yang berbeda dengan selisih $0-5$ ppm atau error mencapai 0,05\%. Hal ini terjadi karena sensor TDS pada pengukuran dapat berubah dalam waktu sepersekian detik sehingga hasil pengujian menjadi tidak stabil. Pengujian juga dilakukan dengan membandingkan sensor TDS dengan alat ukur TDS EC meter dan didapat perbedaan nilai yang berbeda dengan selisih 0-5 ppm atau error 0,04 seperti yang tampil pada Tabel 6.

\subsection{Pertumbuhan Tanaman \\ 3.6.1. Tinggi Tanaman}

Tinggi tanaman $(\mathrm{cm})$ dilakukan untuk mengukur perkembangan tanaman kangkung berdasarkan umur tanaman sehingga dihasilkan data yang akurat. Pengamatan tinggi tanaman dilakukan pada $1 \mathrm{HST}, 5 \mathrm{HST}, 10 \mathrm{HST}, 15 \mathrm{HST}, 20 \mathrm{HST}, 25$ 
Tabel 6. Hasil Pengujian Sensor TDS DFrobot dengan TDS EC Meter

\begin{tabular}{cccccc}
\hline No. & \multicolumn{6}{c}{ Pengukuran } \\
\cline { 2 - 6 } & $\begin{array}{c}\text { TDS meter } \\
\text { (ppm) }\end{array}$ & $\begin{array}{c}\text { TDS Sensor } \\
\text { (ppm) LCD }\end{array}$ & $\begin{array}{c}\text { TDS Sensor } \\
(\mathbf{p p m}) \text { Telegram }\end{array}$ & Selisih & $\begin{array}{c}\text { Error } \\
(\%)\end{array}$ \\
\hline 1 & 18 & 18 & 18 & 0 & 0 \\
2 & 132 & 132 & 132 & 0 & 0 \\
3 & 218 & 220 & 220 & 2 & 0.02 \\
4 & 280 & 278 & 278 & 2 & 0.02 \\
5 & 293 & 294 & 294 & 1 & 0.01 \\
6 & 371 & 370 & 370 & 1 & 0.01 \\
7 & 260 & 462 & 462 & 2 & 0.02 \\
8 & 995 & 999 & 999 & 4 & 0.04 \\
\hline
\end{tabular}

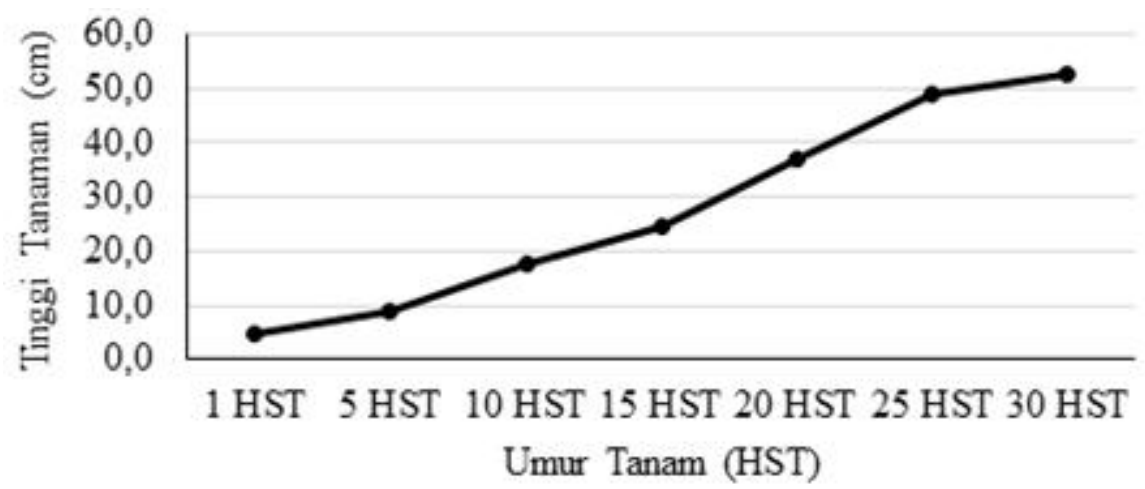

Gambar 8. Perbandingan Tinggi Tanaman Kangkung

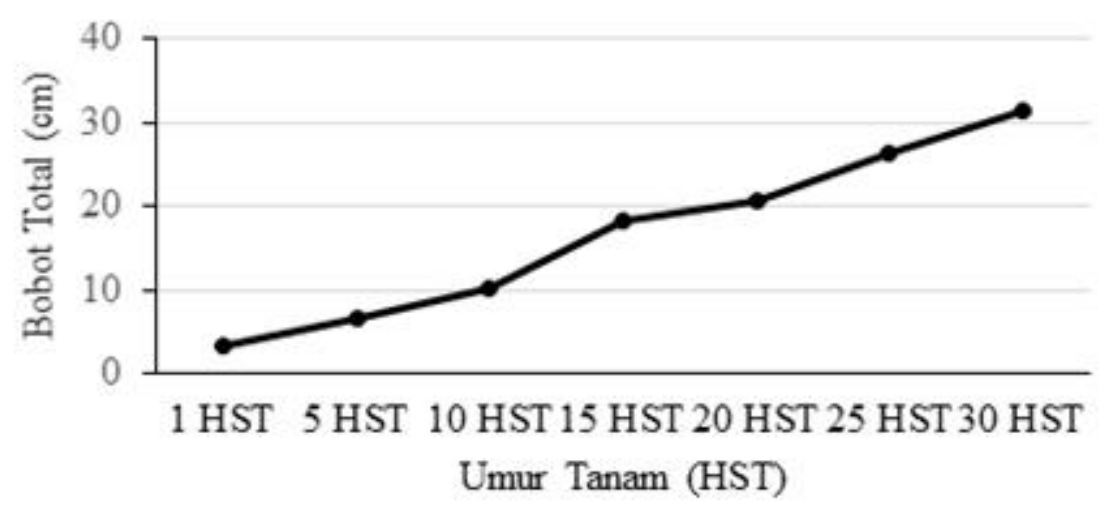

Gambar 9. Perbandingan Bobot Total Basah Tanaman Kangkung

HST dan 30 HST. Pengukuran tinggi tanaman setiap 5 hari selalu mengalami pertumbuhan yang signifikan, terutama pada setelah 10 HST dan mulai melambat pada $25 \mathrm{HST}$, hasil pengamatan dapat dilihat pada Gambar 8.

\subsubsection{Bobot Total Tanaman}

Bobot total tanaman adalah berat tanaman basar pada 1 netpot yang terdiri dari 8 pohon tanaman, pengukuran dimaksudkan untuk mengukur berat yang dihasilkan pada setiap 5 hari. Setiap pengukuran tanaman kangkung mengalami penambahan berat yang signifikan sehingga pada umur 30 HST bobot tanaman mencapai rata 31,25 gram atau dpat dilihat pada Gambar 9.

\section{KESIMPULAN}

Desain alat monitoring ketinggian air menggunakan sensor ultrasonik HC-SR04 dan sensor TDS (total dissolved solid) yang 
terhubung dengan mikrokontroler ESP32 dengan output relay 2 channel, LCD dan telegram. Pengujian ketinggian air dengan perbandingan antara sensor ultrasonik dan penggaris didapatkan error $0 \%$, sedangkan pengujian sensor TDS dengan TDS-03 didapat error 0-4\% dan TDS EC meter error 0-5\%. Monitoring hidroponik rakit apung tanaman kangkung dilakukan dengan sensor ultrasonik diletakan diatas styofoam dan TDS dicelupkan kedalam bak. Relay dipasangkan dengan pompa air dan pompa TDS yang kemudian mentransfer air ke bak penampung melalui pipa PVC. Semua perintah pompa dapat dioperasikan dari jarak jauh melalui aplikasi telegram. Hasil pengukuran pertumbuhan tanaman kangkung menggunakan hidroponik rakit apung pada umur 30 HST, mencapai rata-rata tinggi tanaman 52,63 dan bobot total basar sebesar 31,25 gram.

Penggunaan alat monitoring kangkung hidroponik bisa ditambahkan sensor $\mathrm{pH}$, sensor suhu dan sensor DO untuk melengkapi sensor ultrasonic dan sensor TDS. Sehingga tampilan pada chat bot telegram lebih banyak, sehingga informasi dan perintah yang didapat menjadi lebih banyak.

\section{UCAPAN TERIMA KASIH}

Terimakasih kepada Direktorat Riset dan Pengabdian Masyarakat, Direktorat Jenderal Penguatan Riset dan Pengembangan, Kementerian Riset, Teknologi, dan Pendidikan Tinggi sesuai dengan Kontrak Penelitian Tahun Anggaran 2020 yang telah memberi dana terhadap penelitian ini. Terimakasih juga kepada LPPM UNU Purwokerto yang telah membimbing peneliti dalam melaksanakan Penelitian Dosen Pemula pada masa pandemic Covid 19.

\section{DAFTAR PUSTAKA}

Bayu, W.N. 2016. Tabel PPM dan pH nutrisi hidroponik. http://hidroponikpedia.com/ tabel-ppm-dan-ph-nutrisi-hidroponik/
Cokrojoyo, A., Andjarwirawan, J., dan Noertjahyana, A. 2017. Pembuatan bot telegram untuk mengambil informasi dan jadwal film menggunakan PHP. Jurnal Infra 5(1): 224-227.

Hidayati, N., Rosawanti, P., Yusuf, F., dan Hanafi, N. 2017. Kajian penggunaan nutrisi anorganik terhadap pertumbuhan kangkung (Ipomoea reptans Poir) hidroponik sistem wick. Jurnal Daun 4(2): 75-81.

Sunardi, O., Adimihardja, S.A., dan Mulyaningsih, Y. 2013. Pengaruh tingkat pemberian ZPT Gibberellin (GA3) terhadap pertumbuhan vegetatif tanaman kang-kung air (Ipomea aquatica Forsk L.) pada sistem hidroponik floating raft technique (FRT). Jurnal Pertanian 4(1): 33-47.

Rohadi, E., Adhitama, D. W., Asmara, R. A., Ariyanto, R., Siradjuddin, I., Ronilaya, F., dan Setiawan, A. 2018. Sistem monitoring budidaya ikan lele berbasis Internet of Things menggunakan Raspberry Pi. Jurnal Teknologi Informasi dan Ilmu Komputer 5(6): 745-750.

Susilawati. 2019. Dasar-Dasar Bertanam Secara Hidroponik. UNSRI Press, Palembang.

Wahome, P. K., Oseni, T. O., Masarirambi, M. T., dan Shongwe, V. D. 2011. Effects of different hydroponics systems and growing media on the vegetative growth, yield and cut flower quality of gypsophila (Gypsophila paniculata L.). World Journal of Agricultural Sciences 7(6): 692-698.

Wulansari, A., Suryanto, A., dan Baskara, M. 2019. Pengaruh tingkat EC dan populasi terhadap produksi tanaman kale (Brassica oleracea var. Acephala) pada sistem hidroponik rakit apung. Jurnal Produksi Tanaman 7(2): 330-3387. 